\title{
Design, comunicação e sustentabilidade como fomento de consumo
}

\section{Design, communication and sustainability as consumption promotion}

1 Aline Rodrigues Botelho alinerbotelho@gmail.com

2 Vera Lucia Nojima

1 Docente do curso de Design do Centro Universitário de Volta Redonda - UniFOA e Discente do Doutorado em Design pela
Pontifícia Universidade Católica do Rio de Janeiro - PUC-Rio
2 Docente do curso de Design da Pontifícia Universidade Católica do Rio de Janeiro - PUC-Rio

\section{Resumo}

Este artigo utiliza-se da análise de revisão bibliográfıca para fazer uma breve contextualização sobre consumo e sustentabilidade, analisando de que maneira o design e a comunicação contribuem para o meio ambiente ou se são apenas ferramentas de venda, buscando atender apenas aos interesses mercadológicos.

\section{Palavras-chave}

Design; comunicação; sustentabilidade; consumo.

\begin{abstract}
This article makes use of the bibliographic review analysis to make a brief contextualization about consumption and sustainability, analysing how design and communication contribute to the environment or if they are just selling tools, seeking to meet only market interests.
\end{abstract}

\section{Keywords}

Design; communication; sustainability; consumption.

\section{Como você deve citar?}

Botelho, Aline Rodrigues; Nojima, Vera Lucia. Design, comunicação e sustentabilidade como fomento de consumo. Cadernos UniFOA, Volta Redonda, n. 33, p. 49-56, abr. 2017. 


\section{INTRODUÇÃO}

Muito se sabe acerca dos problemas ambientais, pois são noticiados quase que diariamente pelas mídias, tanto impressas quanto televisivas e digitais. Um dos que mais aguça a preocupação mundial é a redução da camada de ozônio, que age no aquecimento global e proporciona novas formas ao planeta, como o aumento do volume dos mares, pela redução das geleiras; afeta as plantações, provocando, em alguns casos, escassez de alimentos, chuvas não previstas para determinadas regiões, dentre outras situações a que a sociedade não está habituada, pois passa a vivenciar contemporaneamente.

Um dos apontados como principal vilão dos problemas causados ao meio ambiente é o consumo. Muitos autores, sejam eles economistas ou sociólogos, tentam estudar e defini-lo. Este artigo se utiliza da definição de Douglas e Isherwood (2006, p. 83) de que o consumo "utiliza as mercadorias para tornar firme e visível uma série particular de juízos nos mutantes processos de classificação das pessoas e dos acontecimentos". Ou, ainda, segundo Appadurai (2008) que classifica o consumo por meio das relações de troca, divididas em três categorias: troca de presente, permuta ou troca de mercadorias. Este estudo baseia-se apenas na última categoria: a troca de mercadorias mediada pelo dinheiro.

A Revolução Industrial, substituindo homens por máquinas, permitiu "mais tempo livre e, consequentemente, maior acesso ao lazer, ou seja, um novo padrão de bem-estar estava se estabelecendo na sociedade" (SILVA, 2009, p.22). Com o aumento das necessidades no cotidiano das pessoas, alguns autores chegam a associar ao consumo o espaço pertencente anteriormente à religião e à família, passando a ser o foco principal de cada indivíduo. Conforme Cortez (2007, p.20), "o primeiro templo da sociedade burguesa é o supermercado; são as prateleiras abundantemente supridas que satisfazem a liberdade de consumo".

Paralelamente ao consumo, o capitalismo também evoluiu, sendo presenciada, atualmente, a era das multinacionais, empresas espalhadas em todo o mundo, detentoras de diversas marcas que exercem grande poder sobre as demais e sobre a sociedade.

O crescimento desmedido do consumo, que visa ao lucro por meio do materialismo, proporcionou o aumento da extração de recursos naturais e o descarte, contribuindo com os atuais problemas ambientais, exterminando ecossistemas, propagando poluentes tanto de ar quanto de solo e água, dentre outros fatores. 0 cenário atual, dotado de um elevado grau de degradação ambiental, é decorrente dos desejos e necessidades embutidos nos cidadãos, de forma a sustentar o desenvolvimento econômico-industrial na atualidade.

Porém, diante de tantos problemas em níveis globais, a sociedade começa a analisar a forma de enxergar e de se relacionar com as pessoas e o planeta, especialmente no que diz respeito ao consumo, embora possa perceber que o consumidor atual, assim como todos os outros ao longo dos séculos, vive de forma paradoxal, "encoraja e resiste às mudanças" (MCCRACKEN, 2003, p.172) ou deseja o progresso, mas ainda escolhe o passado, como comenta Forty (2007), no livro Objetos de Desejo. Desse modo, podemos comparar o consumidor com Janus, deus da mitologia romana, dotado de enorme prudência, de modo "que o futuro e o passado estavam sempre diante dos olhos" (MITHOS).

Sendo assim, é possível perceber que, mesmo dotada do desejo de consumir, alguns membros da sociedade passou a possuir também um tipo de conscientização. Por meio de mudanças nos hábitos de consumo, os elementos da sociedade começam a exercer a cidadania, passando de "cidadão consumidor" para "consumidor cidadão" (AKATU). Pode-se dizer que, atualmente, o consumo adquiriu uma nova vertente de responsabilidade ambiental, ou seja, as pessoas começam a repensar suas práticas e transformam suas ações na hora do consumo, optando por artigos menos agressivos ao meio ambiente. 
Identificando esse novo nicho de mercado em relação ao consumo consciente, as empresas se empenham em repensar seu posicionamento e seus produtos, pois entendem que a preocupação ambiental que cada pessoa adquire não é algo que se deva restringir somente ao momento da compra. Os clientes buscam históricos sobre as empresas, sua postura com relação a atitudes sustentáveis e procuram por inovações menos agressivas ao planeta. A busca por um posicionamento no mercado faz com que as empresas se associem às estratégias de marketing e design, objetivando conhecer meIhor o consumidor e corresponder a suas expectativas. Autores como Shove (2003) e Sassatelli (2006) abordam como o marketing e a publicidade contribuem para as mudanças das práticas, provocando alterações ecológicas na vida diária da sociedade.

As empresas buscam, ainda, em parcerias com os designers, não só mudar o conceito e o objeto em si, mas meios de agregar valores ecológicos às suas marcas. Um reflexo disso é a coparticipação entre empresas privadas e organizações não governamentais (ONGs):

(...) as empresas começaram a perceber que ações tidas como ecológicas e sociais do ponto de vista da compreensão da população em geral e do mercado, traziam grande valor para as marcas e auxiliavam no crescimento do valor da própria empresa (MARTINS; PONS; RICCETTI, 2008, p.1376-7)

A partir desse panorama sobre os problemas ambientais e consumo, podemos abordar o propósito deste artigo, que busca entender como o design, aliado à comunicação e imbuídos de conceitos de sustentabilidade, torna os produtos mais vendáveis.

\section{DESIGN, COMUNICAÇÃO E SUSTENTABILIDADE}

Como dito anteriormente, no início da Revolução Industrial, o mercado estava livre para o surgimento de qualquer produto, pois não existia demanda e nem tampouco concorrentes. Para tudo o que era produzido havia um consumidor à disposição para comprar.

Essa divulgação crescente dos novos hábitos de consumo foi proposta pelos países desenvolvidos, numa tentativa bem sucedida de ampliar seu mercado e aumentar a venda de seus produtos. Conforme cita Silva (2009, p.24), "este conceito de aumento do status social a partir da posse é promovido de forma massificada pelo conceito do consumo universal de bens". Tal modelo foi adotado pelos chamados países em desenvolvimento.

A partir dos anos 1930, com o surgimento e disseminação mundial do modelo de supermercado, aumentou consideravelmente a procura por novos produtos e, inclusive, o número de fabricantes, intensificando a concorrência. Dessa maneira, cresceu também a forma de divulgação desses objetos. Eles não eram mais adquiridos apenas por suas funções, e sim, pelas mensagens que passavam ao consumidor e pelo status que representavam.

Com a evolução das tecnologias, ficou acessível produzir e oferecer cada vez mais novos produtos. Além disso, de acordo com Appadurai (2008), as estratégias de marketing transformaram produtos comuns em desejáveis. Desse modo, obter novidades tornou-se uma das prioridades da sociedade moderna.

Ter acesso a diferentes produtos e substituir a todo instante um velho artigo é motivo de sedução, na sociedade atual. Obter novos objetos passou a ser sinônimo de status, estilo de vida e, principalmente, de identidade. 0 consumidor busca, através do seu modo de consumo, se expressar, se diferenciar de uma comunidade, se identificar com alguma tribo, mesmo que seja completamente distinta de sua 
origem social. Além disso, impera o que Douglas e Isherwood (2006) chamaram de modelo da difusão da infecção, ou seja, as pessoas usualmente compram o que veem seus amigos desfrutando.

Embutir nas pessoas a prioridade de consumo e o desejo de satisfazer suas necessidades é uma das maneiras de manter o ritmo crescente de lucro, sustentando, desse modo, o capitalismo.

Se um produto não quebra ou não sai de moda, não há necessidade de trocá-lo, o que ocasionaria uma diminuição do consumo e prejuízo às empresas. Nesse intuito de criar demandas, surge a obsolescência, que, como o próprio nome diz, atribui aos objetos um caráter obsoleto, ultrapassado. Os produtos têm um prazo certo para sair de moda, deixar de funcionar ou não satisfazer os desejos dos consumidores. Dentre os tipos de obsolescência, temos duas modalidades: a tecnológica e a planejada.

A obsolescência tecnológica, bastante comum, principalmente, junto aos computadores de hoje em dia, aparece quando se "substitui um produto por outro de desempenho superior" (SILVA, 2009, p. 25). Ocorre, na maioria das vezes, quase que naturalmente, em especial quando se destina ao aperfeiçoamento de uma tecnologia que beneficiará e facilitará seu uso por outras pessoas.

A obsolescência planejada tem um caráter artificial pelo seu modo de ocorrência, cabendo acrescentar que o design tem sido um grande contribuinte para esse modelo. Essa forma abrange dois tipos, sendo um deles o de estilo, que trabalha com os chamados objetos de desejo, aqueles que o consumidor necessita possuir. A obsolescência planejada não é provocada pela baixa qualidade de produtos nem substitui os já existentes por outros aperfeiçoados. Ela aumenta a quantidade de vendas através do desejo embutido nas pessoas. E afeta as diferentes classes sociais que buscam alcançar, através dos produtos, uma distinção que as destaque dentre as demais da sociedade.

A segunda vertente da obsolescência planejada é a de durabilidade, ou seja, quando um objeto tem seu fim decidido durante seu projeto, seja pela "quebra ou desgaste de um item ou de todo o produto, de forma a reduzir a durabilidade do produto por questões mercadológicas" (SILVA, 2009, p. 27). Essa tipologia ocorre também, porque a maioria das empresas busca materiais mais baratos, de qualidade inferior, para manter o nível de produção e o crescimento das vendas aliados a um baixo preço do produto final para o consumidor. Vale salientar que estipular a vida útil de um produto, isto é, seu tempo de utilização pelo consumidor, objetivando vender mais produtos, é considerado crime e, em alguns casos, pode colocar em risco a vida do usuário.

Diante dessas obsolescências que já fazem "parte da estratégia de marketing de muitas empresas", ocorre como consequência o aumento da produção e ainda "fomenta a cultura do descarte" (DOSSIÊ CONHECIMENTO PARA A SUSTENTABILIDADE, 2010, p. 63), tanto de produtos quanto de embalagens e outros materiais.

0 aumento na aquisição de mercadorias ocasiona um agravamento dos problemas ambientais decorrentes da fabricação, uso e do descarte, em especial. Esse último pode ser analisado através da quantidade de lixo produzido por cada município, como é o caso do Rio de Janeiro, que, de acordo com dados da Companhia Municipal de Limpeza Urbana (COMLURB), produziu, somente no mês de novembro de 2011, um total de 98.929 toneladas de lixo.

Além do lixo produzido, temos como impacto também a extração de materiais naturais, cujo excesso de retirada não permite que a natureza renove seus recursos, com contaminação da água, do solo e do ar, tudo isso contribuindo para o desequilíbrio ambiental. 
Diante desse cenário de crise, no qual o progresso, além de proporcionar benefícios, acarreta uma gama de mudanças, principalmente ambientais, há uma conscientização em formação de que os recursos naturais podem se esgotar e acerca de que promover o desenvolvimento sustentável é indispensável para a manutenção do planeta em condições semelhantes à atual. E, embora o consumo, como cita Shove (2003), seja rotinizado e formatado por forças culturais e econômicas, é possível perceber que alguns consumidores têm buscado, em suas práticas, interferir e mudar o cenário atual.

Além de novas possibilidades almejadas pelos consumidores, há de se repensar a forma de produção dos objetos, "os processos por trás dos produtos que utilizamos, os materiais e a energia necessária para produzi-los, o modo como operamos no dia-a-dia e o que acontece com eles quando perdem a utilidade" (THACKARA, 2008, p. 24). Grande parte dessas alterações é prevista no campo do design e é com esse objetivo que surge o design sustentável.

O design sustentável ou voltado para a sustentabilidade busca "apresentar novas perspectivas para refletir e praticar design de forma contextualizada, agindo transdisciplinarmente, considerando as diferenças locais, econômicas e sociais" (QUEIROZ, 2009, p. 157) ou, ainda, segundo Manzini e Vezzoli (2005, p. 20), como uma alternativa de ligar "o tecnicamente possível com o ecologicamente necessário", fazendo "nascer novas propostas que sejam social e culturalmente apreciáveis".

Através de sua criatividade, o designer busca acrescentar conceitos nos produtos, a fim de provocar uma conscientização populacional para o problema ambiental. Para executar novos projetos ecologicamente corretos, alguns fatores devem ser levados em conta, conforme descrevem Manzini e Vezzoli (2005, p. 28):

- Basear-se fundamentalmente em recursos renováveis (garantindo ao mesmo tempo a renovação)

- Otimizar o emprego dos recursos não renováveis (compreendidos como o ar, a água e o território);

- Não acumular lixo que o ecossistema não seja capaz de renaturalizar (isto é, fazer retornar às substâncias minerais originais e, não menos importante, às suas concentrações originais).

Apesar de todos esses norteamentos, não há uma tarja de "ecológico" totalmente aplicável aos produtos. Isso acontece, porque a produção não é totalmente adequada, mesmo que alguns esforços sejam feitos para sua melhoria.

Uma alternativa para checar os processos produtivos é a Análise do Ciclo de Vida - ACV. Por meio desse método, todo o processo é analisado "à chegada da matéria-prima, ao processo de produção, ao transporte, à embalagem do produto, ao seu uso e, por último, a sua disposição final" (CORTEZ, 2007, p. 24). Obviamente, é um processo longo, que ainda deixa muito a desejar, principalmente no Brasil, visto que toda catalogação de materiais e processos tem dados internacionais. Mas, certamente, é um futuro para alterar os modos de produção e mudar as práticas sociais em relação aos problemas ambientais. Como comenta Sassatelli (2006), consumidores éticos devem saber o custo sustentável de suas escolhas, ter ciência do quanto de poluição e recursos foram gastos por cada produto escolhido.

A criação de produtos mais ecológicos não visa alterar de uma só vez a prática de consumo e a aquisição de produtos. Busca-se, inicialmente, adaptar ao já existente alguns conceitos de sustentabilidade, proporcionando a possibilidade de aprendizado, tanto para quem produz quanto para quem compra. Assim, a fabricação de produtos sustentáveis vem com o objetivo de melhoria ambiental 
e reversão do quadro de crise que presenciamos atualmente. Porém, nessas medidas "não deverão ser consideradas somente as vantagens econômicas e sim os possíveis efeitos sobre a comunidade" (LÖBACH, 2001, p. 21-2).

Dessa forma, não cabe ao designer apenas atentar no produto e na maneira de fabricação, mas repensar seu consumidor e suas novas práticas, embora muitas ainda sejam executadas de maneira tradicional.

Objetiva-se, assim, com o design sustentável, a elaboração de produtos realmente ecológicos e que contribuam com o meio ambiente, não se tornando apenas uma estratégia de marketing dos fabricantes para atrair clientes bem intencionados.

\section{CONCLUSÃO}

Com base na revisão bibliográfica realizada para este estudo, podemos afirmar, embora com ressalvas, que as práticas de consumo de uma parcela da sociedade vêm se alterando. É provável que essa alteração seja fruto do ecomarketing ou mensagens de comunicação sobre a sustentabilidade, principalmente decorrentes dos eventos mundiais sobre problemas ambientais ou estratégias de marketing de empresas que estão voltadas para esse nicho de mercado. Nesse ponto, autores como Papanek (1977), Shove (2003), Sassatelli (2006) e Rocha (1985) dialogam, no sentido de acreditar no marketing e publicidade, que "tem como projeto 'influenciar', 'aumentar o consumo', 'transformar hábitos', 'educar' e 'informar', pretendendo-se ainda capaz de atingir a sociedade como um todo" (ROCHA, 1985, p. 26).

Concorda-se com Denis (2000) e Manzini (2008), quando dizem que, apesar de uma parcela ter alterado as práticas e sua forma de consumo, isso não se reflete em uma melhoria em nível ambiental. Apesar de os consumidores que se dizem conscientes optarem por dispender mais dinheiro para comprar produtos ecologicamente corretos, isso não muda o fato de que a construção da sociedade de consumo foi feita, considerando-se o aumento constante da demanda. Sendo assim, "ainda vivemos, infelizmente, em uma sociedade que cultua o excesso como uma vantagem inerente" (DENIS, 2000, p. 220). Apesar de escolherem produtos de baixo impacto, os consumidores tendem a consumir mais, 0 que culmina no aumento da utilização de recursos naturais. Denis (2000) chegou a nomear esse fato como consumismo verde.

Autores como Papanek (1977), Denis (2000) e Forty (2007) corroboram com o pensamento de que o design, como área de conhecimento, é capaz de transformar a sociedade, elaborando ferramentas capazes de moldar o homem e seu ambiente, além de afetar os processos econômicos. 0 design, longe de ser neutro, tem efeitos muito mais duradouros que os produtos efêmeros das mídias, porque podem lançar ideias sobre quem somos e como devemos nos comportar, através de objetos tangíveis.

A reflexão que se pretende desenvolver diz respeito à forma com que o design sustentável, como saber específico da área do design, tem sido abordado. Muito se diz a respeito de inovações tecnológicas em produtos, de forma com que sejam menos agressivos ao meio ambiente. Muitas mensagens comunicacionais também têm sido emitidas aos consumidores, de forma a tornarem o produto mais vendável e aumentar o valor agregado à empresa perante a sociedade, porém, na teoria, pouca coisa tem sido feita. Pouco tem se pesquisado a respeito de como comprovar a veracidade da sustentabilidade nesses produtos ou como criar um sistema em que o próprio consumidor possa identificar, sem receio, os atributos ecológicos dos referidos produtos. 
Acredita-se que, ainda, não seja possível elaborar uma epistemologia sobre design sustentável, pois, conforme Japiassu (1934, p. 10), uma reflexão epistemológica possui como preocupação fundamental "situar os problemas tais como eles se colocam ou se omitem, se resolvem ou desaparecem na prática efetiva dos cientistas". Tendo o design sustentável como campo ainda recente, não dá para saber o que é de fato conhecimento, o que é crença, o que é de cunho ambiental, com o intuito de meIhoria do planeta ou apenas jogada de marketing.

O próprio campo do consumo, se analisado em nível sociológico, tendo como enfoque as pessoas e não a produção, é uma área nova, ainda pouco estudada.

Acredita-se que a melhor maneira de se formar saberes em relação ao design sustentável é criar práticas que possam ser realmente comprovadas por todos, não tendo a dubiedade sobre estratégias de marketing ou melhorias na forma do consumo, transmitindo-se mensagens claras e criando decisões éticas e políticas que sejam facilmente identificadas por todos, e não apenas por especialistas do campo.

\section{REFERÊNCIAS}

APPADURAI, A. A vida social das coisas: as mercadorias sob uma perspectiva cultural. Niterói: EdUFF, 2008.

COMPANHIA MUNICIPAL DE LIMPEZA URBANA. Rio de Janeiro. Disponível em: <http://www.rio.rj.gov. br/comlurb $>$. Acesso em: 12 mar. 2010.

CORTEZ, ATC. A produção de descartáveis na sociedade de consumo atual. In: Consumo sustentável: conflitos entre necessidade e desperdício. São Paulo: UNESP, 2007, pp 17-50.

CORTEZ, ATC; ORTIGOZA, SAG. (orgs.). Consumo sustentável: conflitos entre necessidade e desperdício. São Paulo: UNESP, 2007.

DENIS, RC. Uma introdução à história do design. São Paulo: Edgard Blücher, 2000.

DOUGLAS, M; ISHERWOOD, B. 0 mundo dos bens: para uma antropologia do consumo. Rio de Janeiro: EdUFRJ, 2006.

ECHEGARAY, Fabián. Dossiê conhecimento para a sustentabilidade: tendências para o consumo consciente. Ideia sustentável. Disponível em: <http://www.ideiasustentavel.com.br/pdf/lS17\%20-\%20 Dossie.pdf >. Acesso em: 03 maio 2011.

FORTY, A. Objetos de desejo: design e sociedade desde 1750. São Paulo: Cosac \& Naify, 2007.

INSTITUTO AKATU. Disponível em: <http://www.akatu.org.br>. Acesso em: 20 nov. 2010.

JAPIASSU, HF. Introdução ao pensamento epistemológico. Rio de Janeiro: F. Alves, 1934.

LÖBACH, B. Design Industrial: bases para a configuração dos produtos. São Paulo: Edgard Blücher, 2001.

MANZINI, E. Design para a inovação social e sustentabilidade: comunidades criativas, organizações colaborativas e novas redes projetuais. Rio de Janeiro: E-papers, 2008. 
MANZINI, E; VEZZOLI, C. O desenvolvimento de produtos sustentáveis: os requisitos ambientais dos produtos industriais. São Paulo: Editora da USP, 2005.

MARTINS, N.; PONS, I; RICCETTI, T. 0 papel do design na transição sócio ambiental no mundo contemporâneo. Anais. $8^{\circ}$ Congresso Brasileiro de Pesquisa e Desenvolvimento em Design, São Paulo, 2008.

MCCRACKEN, G. Cultura \& consumo: novas abordagens ao caráter simbólico dos bens e das atividades de consumo. Rio de Janeiro: Mauad, 2003.

MITHOS. Disponível em:< http://mithos.cys.com.br/>. Acesso em: 22 out. 2010.

PAPANEK, V. Design for the real world: human, ecology and social change. St. Albans: Paladin, 1977.

QUEIROZ, L.L. A atuação do design no cenário (in)sustentável. 2009. (tese de doutorado), Puc-Rio, 2009.

ROCHA, E.P.G. Magia e capitalismo: um estudo antropológico da publicidade. São Paulo: Brasiliense, 1985.

SASSATELLI, R. Virtue, Responsibility and Consumer Choice: Framing Critical Consumerism. In: BREWER, J; TRENTMANN, F (eds). Consuming Cultures, Global Perspectives: Historical Trajectories, Transnational Exchanges. London: Berg, 2006, p. 219-250.

SHOVE, E. Comfort, cleanliness and convenience: the social organization of normality. Oxford: Berg, 2003.

SILVA, M.H.G. Design para sustentabilidade e a economia de serviço: o caso de purificação de água por assinatura. 2009. Tese. (Doutorado) - Puc-Rio, 2009.

THACKARA, J. Plano B: O design e as alternativas viáveis em um mundo complexo. São Paulo: Saraiva, 2008. 